\title{
O INCONSCIENTE NA SALA DE AULA
}

Marta D'Agord

Psicóloga, psicanalista, doutora em Psicologia do Desenvolvimento, UFRGS; professora do Departamento de Psicanálise e Psicopatologia do Instituto de Psicologia da UFRGS.

RESUMO: Este artigo apresenta alguns achados de uma investigação sobre as formações do inconsciente em situações de aprendizagem, cujos sujeitos são dois grupos de escolares com 11 anos de idade. As formações do inconsciente que se manifestaram nessas situações de aprendizagem analisadas são os chistes e 0 que denominamos devaneios em alteridade. 0 trabalho mostra a contribuição da teoria psicanalítica para 0 entendimento dos processos de pensamento. 0 artigo discute a separação entre afetos e cognição e sugere que os campos conceituais diferenciados aos quais pertencem o sujeito cognitivo e 0 sujeito do inconsciente não se opõem mas, em suas diferenças, enriquecem a compreensão dos processos de pensamento.

Palavras-chave: Psicanálise, formações do inconsciente, chistes, devaneios em alteridade, sujeito do inconsciente, sujeito epistêmico.

ABSTRACT: Unconscious formations in the classroom. This article presents some findings of an investigation into the unconscious formations (Unbewusste Bildung) in learning situations whose subjects are two groups of eleven-year old students. The formations of the unconscious that appeared in these learning situations are the jokes (W itz) and what we call day-dreaming in otherness (alterity). The work shows the contribution of the psychoanalytical theory to the understanding of the processes of the thoughts. The article discusses the separation between affection and cognition and suggests that the different conceptual fields concerning the cognitive subject and the unconscious subject do not oppose each other, but in their differences they enrich the understanding of the processes of thought.

Keywords: Psychoanalysis, unconscious formations (UnbewusteBildung), jokes (W itz), day-dreaming in otherness (alterity), unconscious subject, epistemic subject. 
teoria psicanalítica chama de formações do inconsciente os sintomas, os so-
nhos, os chistes, os atos falhos e as lembranças encobridoras. Essas forma-
ções são efeitos conhecidos dos processos psíquicos inconscientes. U ma forma-
ção do inconsciente é uma elaboração psíquica e simbólica, cuja forma depende das inscrições psíquicas, ou memória inconsciente, em um sujeito.

Em nossa cultura está presente a concepção de que razão e emoção são distintas e independentes. Em Psicologia encontramos uma interpretação segundo a qual há, nas aprendizagens, uma dimensão afetiva separada de uma dimensão cognitiva. U ma outra interpretação poderia dizer que o afetivo seria como um agente externo ou complementar nas aprendizagens sempre que essas são concebi das como exclusivamente cognitivas.

Mas como seria possível isolar o processo cognitivo do conjunto das vivências de um sujeito? Essa pergunta surgiu ao percebermoso equívoco presente natentativa de utilizar as expressões "afetivo ou cognitivo" para descrever um conjunto de fenômenos observados em situações de aprendizagem. Como veremos, quando, em uma situação de aprendizagem, os sujeitos fal am livremente sobre o tema investigado, não há como deter o rico processo de associações que uma palavra ou tema evoca em cada sujeito. Observa-se, então, que os enunciados não se limitam a uma dimensão denotativa, mas que a riqueza das associações expande o tema inicial. Ora, esse processo conotativo não pode ser considerado nem puramente cognitivo nem puramente emocional ou afetivo. Sabemos apenas que é um processo determinado pela imersão dos sujeitos em um mundo de linguagem.

Os sujeitos aos quais nos referimos neste trabalho são dois grupos de escolares de 11 anos de idade, cujos enunciados foram obtidos através do registro em fita magnética do que era verbalizado durante essas situações de aprendizagem. Vale observar que essas situações de aprendizagem, denominadas " projetos de aprendizagem", são atividades de pesquisa em grupo orientadas por professores, nas quais o tema investigado surge das questões propostas pelos próprios alunos. O primeiro grupo, com oito participantes, reuniu-se a partir de uma dúvida comum: "Por que os seres não caem daTerra?" . 0 segundo grupo, com 16 participantes, reuniu-se em torno da temática "O espaço e o sistema solar".

A teoria psicanalítica das formações do inconsciente nos guiará na análise desses enunciados. E para nos auxiliar a identificar os marcos de um processo de aprendizagem, contaremos com a epistemologia genética piagetiana.

\section{OS CHISTES}

O grupo que pesquisava "Por que os seres não caem daTerra?" começou o seu processo de investigação a partir da hipótese da existência de um grande ímã dentro daTerra. Essa hipótese estava vinculada ao que os participantes chamavam de fenômeno do magnetismo enquanto causa da atração de todos os seres, vivos ou 
não, para aTerra. Ao final do segundo encontro de pesquisa, surgiu a concepção de gravidade. A partir desse momento, eles estabeleceram a seguinte diferenciação: “ $A$ gravidade é uma força que atrai os seres para o centro daTerra. 0 magnetismo é uma força que atrai os seres uns aos outros."

Quando o grupo apresenta para o seu orientador os seus primeiros achados de pesquisa, se estabelece o seguinte diálogo:

Prof.1: Vocês conversaram muito, e pesquisaram em livros e ele [G] trouxe uma informação e eu ouvi. Eu quero agora que vocês me digam se eu entendi. Ele pesquisou e encontrou que um ímã atrai ferro, níquel, cobalto e aço. E agora vocês estavam dizendo que os corpos não caem da terra porque têm magnetismo. E aí eu vou perguntar para vocês: A minha pele é feita de ferro, é feita de níquel, de cobalto, de aço?

Todos: Não.

Prof.1: E o meu músculo, éfeito de ferro, de níquel, de cobalto, de aço?

Todos: Não.

Prof.1: E o meu 0sso, é feito desses materiais?

Todos: Não.

Prof.1: Então eu fiquei com uma dúvida, se o ímã só atrai ferro, níquel, aço e cobalto, e nós não caímos da terra porque a terra tem magnetismo, como é que eu sou atraído pela terra, se eu não sou feito desses quatro materiais?

KAL: É porque tem outros tipos de magnetismo. Tem aquelas coisas quando a gente passa a caneta no cabelo e depois a caneta puxa o papel.

Prof.1: Mas o que é essa coisa que puxa papel?

KAL: Não sei...É um tipo de magnetismo também.

Prof.1: Mas aí não fecha com o que ele disse. Ele disse que o ímã só atrai aquelas quatro substâncias e tu estás me dizendo que o magnetismo atrai papel. Magnetismo não é imã?

KAL: Magnetismo não é só ímã.

WAN: Não ésó ímã.

Se, no primeiro momento, ainda vemos uma generalização indutiva: "É porque tem outros tipos de magnetismo", no segundo momento: "Magnetismo não é só ímã", a diferenciação anterior é projetada para um patamar mais alto. A classe do magnetismo é integrada numa grande classe que pode envolver várias subclasses.

Surge, então, um exemplo para provar que nem todo magnetismo é ímã. Os alunos apresentam ao professor um tipo de magnetismo que não é causado por ímã, eque é denominado eletricidade estática. 
Prof.1: Qual a diferença entre ímã e magnetismo?

(Enquanto os outros falam, ZIA faz a demonstração da caneta que atrai papeizinhos depois de ser passada no seu cabelo, no que é imitada por duas colegas.)

Prof. 1: 0 que é isso?

ZIA: Isso é eletricidade estática.

Prof.1: El etricidade estática?!

ZIA: A eletricidade que vem do nosso corpo. Li num livro... na 4⿳亠丷a série.

KAL: Ah, também já vi isso!

WAN : Será que não são os piolhos que pegam o papel? (risos)

O enunciado deWAN produziu vários efeitos, a começar pelos risos que promoveram uma ruptura no discurso que vinha sendo desenvolvido. Atéa intervenção deWAN, o grupo assistia à demonstração de uma experiência de el etricidade estática dirigida por ZIA. E o professor mostrava-se reticente em relação a mais uma tentativa dos alunos de manutenção da hipótese do magnetismo.

Em um raciocínio inferencial, o sujeito deduz relações entre objetos sem depender de observáveis, mas apoiado nas coordenações que faz sobre esses observáveis. Assim, com relação aos processos inconscientes de equilibração dos sistemas cognitivos, ZIA eWAN apresentam raciocínios inferenciais, sob a forma de relações de causa e efeito.

Para ZIA, a ação de passar a caneta no cabelo (causa) faz com que "a eletricida de estática, a eletricidade quevem de nosso corpo", seja transmitida para a caneta que passa a atrair papel (efeito). A transmissão da eletricidade do corpo para a caneta não é um observável, mas uma inferência. ParaWAN, os piolhos seriam a causa da atração que a caneta exerce sobre os papeizinhos. Os piolhos teriam passado do cabelo para a caneta e, agora, na caneta, estariam "pegando" o papel.

O enunciado "Será que não são os piolhos que pegam o papel?" apresenta qua tro características de um chiste segundo a definição proposta por Freud (1905c): um enunciado caracterizado pela brevidade (1), lúdico (2), que irrompe espontaneamente (3) e provoca risos no grupo de ouvintes (4).

Trata-se de um chiste produzido com a técnica do raciocínio absurdo (nonsense) e na qual dois fatos de ordens distintas, a saber, os piolhos ea eletricidade estática, são tratados como se estivessem relacionados. No que se refere aos processos inconscientes, essa síntese corresponde ao que Freud (1905c) denominou de uma condensação (Verdichtung), isto é, uso múltiplo do mesmo conceito, nesse caso 0 conceito de atração.

Outro processo inconsciente que aparece nesse chiste é o deslocamento (Verschiebung). No enunciado deWAN, o conceito de atração é deslocado do contexto dos fenômenos astrofísicos (força da gravidade), e passa a ser aplicado à concepção de atração como fenômeno anímico, "os piol hos que pegam o papel". 
Condensação e deslocamento são os processos inconscientes que produzem 0 achado ${ }^{1}$ que aparece na forma do chiste: "são os piol hos que pegam o papel" . 0 chiste irrompe justamente após várias tentativas de explicação para o fenômeno da atração. Surgira a hipótese da eletricidade estática, e, antes, havia aparecido a do grande ímã dentro daTerra. Além dessas duas, formulara-se também a hipótese do calor como causa da atração que a Terra exerce sobre os seres. A hipótese em forma de chiste não fugia, portanto, ao estilo das enunciações, senão por um detalhe, seu conteúdo era declaradamente absurdo.

Esse chiste distorce em nonsense a descoberta que a colega de WAN acaba de apresentar. E, através do nonsense, WAN furta-se a duas dificuldades. Por um lado, ele resiste a qualquer mudança nos conceitos que tem por estabelecidos (atração gravitacional e magnetismo são a mesma coisa). Por outro lado, ele resiste a uma nova explicação que aparecera para o fenômeno da atração, a eletricidade estática, para a qual ele não estabelece ai nda uma significação.

Podemos analisar este chiste a partir de dois enfoques: 0 enfoque do paradoxo lógico e o da economia psíquica. Segundo o primeiro deles, nesse chiste se confundem coisas diferentes em uma mesma relação ( condensação): os piol hos estariam atraindo o papel, assim como a força de gravidade daTerra atrai os seres, ou a eletricidade estática atrai o papel. Trata-se de uma ligação ( condensação) arbitrária, e por isso nonsense, entre os piol hos e a força de atração. 0 nonsense segue o princípio do prazer e não a razão lógica, preferindo encontrar similaridades mesmo onde não há, em vez de ter que separar o que édiferente.

Com o chiste sobre os piolhos, WAN propõe uma solução para o problema e, dessa forma, libera seu pensamento. N esse sentido, a irrupção de um chiste é comparável a uma "absence, um repentino relaxamento da tensão intelectual, e então, imediatamente, lá está o chiste - em regrajá vestido em palavras" (FREUD,1987a, VIII, p. 192). ${ }^{2}$

Isso que Freud chama de relaxamento da tensão intelectual corresponde ao que, no chiste do sujeito WAN, poderíamos chamar de suspensão da inibição, na medida em que, com a elaboração do chiste, houve uma liberação do pensar. Esse processo ocorreu através do encontro de duas cadeias de pensamento de origens diferentes: o magnetismo e a eletricidade estática, que se juntam para formar uma nova hipótese: "será que não são os piolhos que pegam o papel?" Essa associação, mesmo que logicamente sem sentido (nonsense), fez sentido para o grupo, isto é, foi inteligível. Uma prova disso éo riso da audiência.

\footnotetext{
${ }^{1} 0$ termo luso-brasileiro "achado" lembra a expressão francesa trouvaille, que designa o fato de descobrir ou de ter uma idéia original de maneira feliz.

20 processo do chiste na primeira pessoa produz prazer pela suspensão da inibição (1987, VIII, p. 182) [durch Aufhebung von H emmung, GesammelteWerke, VI, p. 177].
} 
Pode-se ainda considerar que esse chiste contra a razão lógica assume a forma da negativa cuja estrutura Freud (1925h) encontrou na maneira de os pacientes formularem suas idéias durante o trabalho analítico:

"O senhor pergunta, quem pode ser essa pessoa no sonho. Não é a minha mãe." Emendamos isso para: 'Então é, a mãe.' Em nossa interpretação, tomamos a liberdade de desprezar a negativa e de escolher apenas o tema geral da associação. É como se 0 paciente tivesse dito: 'É verdade que minha mãe me veio à lembrança quando pensei nessa pessoa, porém não estou inclinado a permitir que essa associação entre em consideração."' (FREUD, 1987a, XIX, p. 295)

Freud toma de empréstimo à filosofia a concepção lógica de negatividade para denominar o processo pelo qual se nega algum conteúdo do pensamento, mas, nessa negação, o conteúdo negado (recalcado) é reconhecido como tal no próprio processo de ser negado. Haveria duas formas de rejeição: por julgamento ou por recalcamento. Na negativa, há uma rejeição por julgamento, de algo que estava recalcado e que irrompeu. U m conteúdo de representação ou de pensamento recalcado pode penetrar na consciência, sob a condição de se deixar negar. A negativa ou denegação ${ }^{3}$ é um modo de tomar conhecimento do recalcado, no fundo já uma suspensão do recalque, mas na verdade nenhuma aceitação do recalcado.

Assim, apresentando um raciocínio absurdo, WAN admite a distinção entre os diversos fenômenos. Pois o que estaria inconsciente e se afirmaria através do nonsense seria, paradoxalmente, o pensamento lógico, a diferenciação entre as diversas ordens defenômenose, por conseguinte, a distinção entre hipóteses válidas e hipótesesnão válidas.

Portanto, nessa situação de aprendizagem, a irrupção de um chiste não impediu o trabal ho de investigação, pelo contrário, contribuiu para o processo de pensamento de um determinado conceito.

\section{OS DEVANEIOS EM ALTERIDADE}

Nos registros do segundo grupo de "aprendizagem por projetos" surgiu outraformação do inconsciente atuando também em colaboração com o processo de aprendizagem. Essa formação do inconsciente foi denominada devaneio em alteridade por se tratar da produção de uma narrativa na primeira pessoa, em que a singularidade do desejo é enunciada a partir da transformação de elementos enunciados por

\footnotetext{
${ }^{3}$ A edição brasileira traduz Verneinung por Negativa. Os franceses traduzem de duas formas: Laplanche (1985) traduz por négation (negação); e Delrieu (1997) traduz por dénégation (denegação). A análise de Jean Hyppolite (LACAN, 1998) confirma essa tradução ao observar que a expressão freudiana etwas im Urteil verneinen significa um desjuízo.
} 
outros participantes do grupo. Esses devaneios apareceram no grupo que pesquisava "O espaço e o sistema solar".

GAL: Eu tava vendo que um planeta, lá, pode ser o planeta X. A gente demoraria 28 anos para ir e 28 anos para voltar desse planeta. E teria passado quatro milhões de anos naTerra.

AMI: E naTerra todos estariam mortos.

LUM: Quando eu era menor, via na tevê naves queiam, para eles demorava um tempo e naTerra demorava outro.

GAL: É que aTerra gira. E passam os anos. E a nave, ela não fica girando. Ela vai, vai, de um jeito só. E quando chega lá a Terra gira e passam os anos.

LUM: É que nem no Japão e nós. Eu ficaria com ciúmes se quando eu nascesse o meu pai viajasse para o planeta $X$, quando el voltasse, ele estaria mais novo do que eu.

GAL: Eu vi o filme Contato e falava disso. Aí a mulher ia casar, mas ela tinha que ir para o espaço. Ele não queria ir porque já teria morrido toda a família e só eu estaria viva, mas seria bom porque poderia contar o passado. Depois de quatro milhões de anos eu estaria na $5^{2}$ série, por exemplo, eu saberia um pouco mais porque vivi aquele passado. 0 passado faz parte da nossa vida, porque a gente veio do passado.

CAR: Bem que eu gostaria de fazer isso, ficar quatro milhões de anos no espaço. Passou quatro milhões de anos aqui e eu volto para aTerra e conto tudo o que aconteceu hoje, no passado, 1998. Porque daí eu vou ser famoso e todo o mundo vai me conhecer.Vão colocar naTV "não sei o quê" de 1998 e vão me chamar.

AMI: Se existir tevê, se existir humanos.

MAT:Tu não vai só ir e voltar. Acho que não é comprovado 28 anos, porque tu podes ficar lá um tempo.

LUM: Não vai ser mais novidade. Daqui a quatro milhões de anos já terão inventado o ônibus espacial pra todo mundo.

No devaneio de LUM: "eu ficaria com ciúmes se quando eu nascesse o meu pai viajasse para o planeta $X$, quando ele voltasse, ele estaria mais novo do que eu", chama a atenção a manifestação do desejo em relação ao pai. LUM interage com a narrativa da colega, inserindo-se nessa narrativa, isto é, integrando, em um mesmo processo, sujeito de desejo e sujeito de conhecimento. Há aqui uma situação que demonstra a articulação, pela palavra, do que é chamado de cognitivo e do que é chamado de afetivo pela psicologia. Millot (1987) diria que, nessa possibilidade de LUM realizar sua fantasia na forma de devaneio, uma pedagogia analítica estaria se realizando.

"O sonho demonstra que o desejo pode reconhecer-se com isso: o desejo se 'realiza' no dizer. Este poderia ser o programa de uma educação de orientação 
analítica. Como a psicanálise o demonstra, a potência da razão reside nas virtudes da palavra." ( MILLOT, p. 106)

A atividade de projetos onde os al unos expressam livremente o que imaginam durante o processo de encontro com o objeto de conhecimento permite a "realização" do desejo. Se a potência da razão reside nas virtudes da palavra, devemos perguntar se as fantasias formuladas em voz alta, como devaneios em alteridade, exercem algum efeito sobre o processo de conhecimento ou são coadjuvantes desseprocesso.

Os devaneios em al teridade aconteceram em uma determinada situação que, pela liberdade de expressão proporcionada, pode ter influenciado o seu surgimento. Neste caso, os sujeitos "navegaram" pela Internet e depois trocaram idéias e experiências entresi.

O leitor perguntaria: será que eles distinguem realidade de fantasia? Sem dúvida, todos distinguem, mas isso não os impede de explorar ao máximo a sua criatividade. GAL narra um filme, mas, durante a narrativa, ela se torna personagem. LUM e CAR devaneiam associando livremente sobre o conteúdo da narrativa de GAL. A participação de AMI é diferente, ela não devaneia, mas toma sobre si a responsabilidade de lembrar aos seus interlocutores a diferença entre realidade e fantasia. Essa diferença de posição não impede que todos se escutem entre si, ou mel hor, que cada um escute as fantasias verbalizadas do outro e aí se insira como personagem.

Freud (1908e/ 1987) explica a construção de devaneios como um substitutivo para o brincar. Quando a criança está crescendo, aos poucos abandona o brincar com objetos reais, passando então a brincar em fantasia, isto é, com objetos fantasiosamente construídos: “Em vez de brincar, ela agora fantasia. Constrói castelos no ar e cria o que chamamos de devaneios (Tagträumen)" (p.151).

As situações de projetos de aprendizagem acima, e aquelas que anal isaremos a seguir, mostram que o desejo, por estar vinculado à constituição psíquica do sujeito, isto é, à sua singularidade, apresenta-se em todos os momentos de sua vida, inclusive nas situações de aprendizagem. Os devaneios que aparecem nas situações de aprendizagem analisadas neste trabal ho demonstram a indissociabilidade entre os desejos e os processos cognitivos, como Freud (1908e) já observara:

"O trabal ho mental vincula-se a uma impressão atual, a alguma ocasião motivadora no presente que foi capaz de despertar um dos desejos principais do sujeito. Dali retrocede à lembrança de uma experiência anterior ( geralmente da infância) na qual esse desejo foi realizado, criando uma situação referente ao futuro que representa a realização do desejo." (FREUD, 1908, IX, p. 153). 
Esse processo pode ser encontrado no discurso de CAR, o menino cujo devaneio é conduzido pelo desejo de se tornar famoso. $E$, como veremos adiante, também está presente na personagem do filme referido por GAL.

No filme Contato, ${ }^{4}$ há uma passagem na qual é possível identificar a frase de GAL: "Quando você voltar, todas as pessoas que você ama terão morrido". Essa frase refere-se à relatividade do tempo, fenômeno que poderia ser observado pelo passageiro de uma nave que viajasse a uma vel ocidade próxima da velocidade da luz. Essa situação é vivida pela personagem do filme que pilotará solitariamente uma nave construída para uma viagem ao centro da Galáxia.

$\mathrm{O}$ devaneio de LUM lembra a situação da personagem principal do filme. $\mathrm{Na}$ sua viagem ao espaço, em uma nave construída para viajar na velocidade da luz, a personagem do filme encontra a imagem de seu pai. Este lhe aparece com a mesma idade que tinha quando ela era criança. Mas antes que el a possa ver outras pessoas, a imagem se desfaz e ela volta para a Terra. Em seu retorno, o maior desafio da personagem, Dra. Arroway, é, então, explicar para seus pares que ela realmente viajou no tempo e no espaço, tentando convencer os incrédulos, para os quais a sua viagem teria mal ogrado, pois a nave apenas teria mergulhado no interior da plataforma de lançamento e o intervalo entre o tempo de início do lançamento e o tempo de término da operação foi tão breve que seria impossível que todos os acontecimentos por ela relatados tivessem acontecido de fato.

N esse grupo de aprendizagem por projetos, al guns participantes buscam certezas instituídas, enquanto outros elaboram fantasias e devaneios para pensar 0 mundo. Esse é o caso de GAL, LUM eCAR. Os três não se preocupam, como AMI, em distinguir o queérealidade e o queéfantasia. Pelo contrário, aproveitam o que descobrem sobre a real idade para acrescentar fatos e conteúdos às suas fantasias. N essa situação, a oposição entre realidade e fantasia, ou realidade e brincar, não é uma oposição excludente, mas uma oposição determinante, no sentido de que os conteúdos de realidade são utilizados para enriquecer a fantasia.

Ora, as fantasias e devanei os são processos inconscientes que reúnem características do pensamento consciente, na medida em que se apresentam de forma organizada e com sentido. Esses processos podem ser compreendidos a partir da concepção freudiana de um trânsito ou comunicação entre os sistemas inconscientee pré-consciente.

"Deve-se dizer que o Ics continua naquilo que conhecemos como derivados (Abkömmlinge), que é acessível às impressões da vida, que influencia constantemente 0 PCS, e que, por sua vez, está inclusive sujeito à influência do Pcs." (FREUD, 1987a, XIV, p. 218)

${ }^{4} 0$ roteiro do filme baseia-se na obra homônima de Carl Sagan (1997). 
Caon (1998) propõe a concepção de um inconsciente aprendentee ensinante, respaldando-se nessas vias de acesso do pré-consciente ao inconsciente:

“Essas vias não são apenas as formações do inconsciente consideradas como lembranças encobridoras, sintomas, atos falhos, chistes. São, de fato, infiltrações do inconsciente no pré-consciente e consciente e vice-versa." (CAON, 1998, p. 48)

0 processo que foi observado em alguns participantes do grupo, a saber, 0 enriquecimento da fantasia pelo conhecimento, seria, então, uma demonstração da cooperação entre inconsciente e pré-consciente. Pois as fantasias seriam, segundo Freud (1915e), derivados dos impulsos inconscientes que utilizam todas as aquisições do sistema consciente, mas permanecem inconscientes. No caso dos partici pantes, suas fantasias manifestam-se enquanto devanei os em voz alta, isto é, são inconscientes até o momento em que são enunciadas, assumindo, então, a forma discursiva.

Não escapa a um ouvido atento o processo dialogal no grupo. Mais do que uma tolerância à fantasia de cada um, ocorre no grupo uma produção criativa em alteridade. 0 que LU M traz é aproveitado por GAL, e, por sua vez, por CAR. N ão há competição quando todos estão ordenados pela associação livre coletiva, na medida em que, quanto mais elementos são trazidos por cada um mais rica será a construção de todos.

Pode-se, lembrando Freud (1908), afirmar que eles estão criando coletivamente teorias para explicar aquilo que mais temem. No caso, a morte, que aparece como a perda de um ente querido (como a personagem do filme), ou como 0 futuro desaparecimento dos seres humanos. Assim, o temível deixa de provocar nos jovens participantes o terror do real. 0 real, passando pelo crivo simbólico de uma explicação, passa a constituir um objeto para pensar.

Metapsicologicamente, o devaneio em al teridade poderia ser definido como um processo de comunicação entre inconscientes. Esse processo émuito conhecido da humanidade. Trata-se da mesma forma de comunicação que encontramos desde a antigüidade clássica grega, quando o público de uma representação trágica se emocionava, identificando-se com os personagens. Os espectadores purificavam-se ( catarse) das mesmas paixões das quais sofriam os heróis. Como nos dias atuais, quando liberamos as tensões de nossas mentes através da leitura das fantasias e devaneios dos escritores criativos (FREUD, 1908).

O leitor argumentaria contra uma universalização da hipótese dos devaneios na aprendizagem, apoiando-se em um fragmento de Freud (1915), no qual ele observa que uma divisão acentuada e final entre o conteúdo dos sistemas inconsciente e pré-consciente não ocorre até a puberdade. Assim, concluiria o leitor, os devaneios em alteridade só poderiam acontecer entre crianças, e jamais seriam 
possíveis num grupo de adolescentes ou adultos. Endossamos essa objeção com a observação de que os adultos preferem, como já escrevia Freud (1908), confessar suas faltas do que confiar a outro suas fantasias e estas, assim como o brincar, são consideradas atividades infantis.

Poderíamos, ainda, observar ao cético leitor que a produção científica pode começar por um devaneio e progredir até chegar à sua demonstração. N essa perspectiva, os devaneios em alteridade poderiam ser considerados um estilo de pesquisar apoiado na imaginação eno brincar. Este estilo éum indicador de que estamos diante de uma das formas do que Papert eTurkle (1990) chamaram de estilos de aprendizagem.

“Onde Piaget viu diversas formas de conhecimento em termos de estádios de um ponto final e finito da razão formal, nós vemos diferentes aproximações ao conhecimento como estilos, cada um válido em seus próprios termos."

Podemos, então, incluir os devaneios entre os estilos de aproximação ao conhecimento. 0 que caracterizaria diversos estilos de aproximação ao conhecimento seria, utilizando uma expressão criada por Papert (1985) , o uso de diferentes “objetos para pensar com" (objects to think with).

Para ilustrar essa idéia, Papert (1985) relata uma experiência pessoal. Narra que, desde os dois anos de idade, era apaixonado por engrenagens, e que essas serviam de model o para pensar. Mais tarde, já na escola, as engrenagens serviram como modelos, facilitando o seu acesso a idéias abstratas. Essa experiência, afirma Papert ( 1985) mostra que "o que um indivíduo pode aprender e como ele aprende depende dos modelosque tem disponíveis" (p. 13).

Assim como as engrenagens de Papert, os devaneios funcionam como instrumentos para a produção de modelos. Mas não se trata de um modelo e sim de vários. 0 que eles têm em comum é que são sustentados por al guma paixão e por lembranças. E, a partir dos devaneios, como método, os sujeitos el aboram anal ogias, as quais permitem que uma experiência seja abstraída. Só o que foi experimentado, isto é, o que foi significativo e que por isso se tornou experiência, pode ser um modelo.

Os devaneios (Tagträumen), também chamados de sonhos diurnos, compartiIham com os sonhos a finalidade da realização de desejos, mas, contrariamente aos sonhos, os devaneios trabal ham com a participação da consciência e do discurso instituído. É o caso da atividade de devanear que apareceu nos enunciados, uma vez que ela se caracterizou por fomentar o processo de construção de pensamento sobre um tema.

A concepção psicanalítica de uma formação do inconsciente refere-se ao campo do que é singular. Essa singularidade está relacionada ao que é constituinte, no 
sentido do que causou determinada estruturação, ou configuração. Está em questão a tentativa de explicação do posicionamento do sujeito em relação ao próprio desejo. 0 que se revela em uma manifestação inconscienteé a verdade desse desejo. E já que a singularidade acompanha-nos sempre, ela aparece também em uma situação de aprendizagem.

0 inconsciente freudiano já foi pensado como atuando na profundidade, como um funcionamento subjacente a todo ato ou pensamento. Mas a releitura deFreud por Lacan teve como efeito re-situar o topos da atividade e dos efeitos do inconsciente, desde então pensados como superfície discursiva. 0 discurso faz ato inconsciente quando re-situa o sujeito que enuncia. Não está em questão a separação entre afetivo e cognitivo, mas a articulação entre tudo o que "engata" o sujeito no discurso, seja o discurso científico, seja a narrativa fantasiosa ou o devaneio em alteridade. Todas as formas discursivas exercem sobre os sujeitos um efeito, o efeito significante. Isso se deve ao fato de que se éatravés de enunciados que se formula um problema ou questão de pesquisa, o sujeito que enuncia sempre estará incluído no problema que ele pretende investigar. Não está, pois, em questão a separação entre o que é afetivo e o que é cognitivo, mas sim tudo o que ésignificativo, isto é, tudo que exerce um efeito significante sobre o sujeito, tomado em sua singularidade, isto é, em seu percurso como sujeito desejante.

Observou-se, nas situações de aprendizagem, que os devaneios tomavam a forma de breves narrativas nas quais apareciam implicações significantes. Isto é, segundo a concepção piagetiana, relações de significação sem o estabelecimento de relações necessárias entre proposições. Por sua vez, as implicações significantes, enquanto hipóteses de investigação, não se distinguiam, para os sujeitos, das outras formas de hipóteses, aquelas que se fundavam sobre inferências causais ou sobre inferências lógicas.

0 processo de devaneios em alteridade é, então, o cenário do confronto e do trânsito entre as narrativas fantasi osamente construídas e as inferências lógicas até que, em al gum momento, as primeiras se transformem pela atuação das últimas. Mas, aqui, o papel dos interlocutores, sejam colegas da mesma idade, sejam professores, vai ser fundamental.

\section{A REPETIÇÃO}

A repetição apareceu claramenteno processo de escolha do tema, na forma de um móbil da ati vidade de construção de conhecimento, determinado por uma insistência significante. Isto é, na escuta da história do engajamento de cada sujeito no tema de investigação, foi encontrada uma repetição de significantes, enquanto tra ços de lembranças inconscientes, retomados e reelaborados em conteúdos de pesquisa, no caso, conteúdos deAstronomia.

A escolha de cada planeta tem um motivo específico. No diálogo entreADU e 
ROG, que escolheram pesquisar sobre as galáxias, a repetição significante enunciase quando ROG diz, "eu ouvi o nome galáxias, vi que tinha a ver com o sistema solar e quis aprender o que era". É nesse momento queADU lembra que na segunda série queria ter um ioiô galax, "foi um dos melhores ioiôsque já vi". Ele nunca ganhou o ioiô (porque era preciso "juntar não sei quantas tampinhas"), mas acabou estudando as galáxias e "reencontrando" o ioiô: "eles botaram galax prá galá xia, porque ele éassim ó, ele é marronzinho com um monte de coisas brilhando, o marrom deveria ser o componente, e o brilhando deveria ser a estrela".

0 menino que devaneava com um brinquedo recriou esse objeto perdido através de uma pesquisa, em que, aos pou cosfoi descobrindo que "as galáxias estão se afastando mutuamente em uma velocidade proporcional às suas distâncias; 0 universo é composto de galáxias; essas são compostas por estrelas, cometas, planetas, meteoros e asteróides também; nós estamos no planeta Terra, que faz parte do sistema solar, que se localiza em um dos braços (parte mais visível) da galáxia denominadaVia-láctea." (enunciados deADU duranteo projeto).

0 relato deADU mostra que podemos, hoje, desejar um ioiô. Amanhã, desse ioiô, restam apenas os significantes que nos convocam a realizar uma pesquisa. E prosseguimos na perseguição não mais do objeto, mas das suas metamorfoses significantes. É nesse sentido que Lacan afirma queo objeto de desejo émetonímico: o objeto de desejo sendo objeto do desejo do Outro, e o desejo sendo desejo de Outra coisa. ${ }^{5}$

N esse caso, o ioiô não seria o objeto originário de desejo, mas a sua entradana cadeia significante do discurso deve-se a al gum traço que o vinculou metonimicamente a este objeto, este sim o objeto originário de desejo, o qual Lacan convencionou chamar de "objeto a".

0 caso ADU mostraria então a superação da concepção de que o afetivo seria o motor da aprendizagem. Na medida em que, como diria Cifali (1998), essa situação mostra que o saber é'natural mente' investido do ponto de vista do afeto. ${ }^{6}$

Mas como trabalhar com o registro do investimento e com o registro do significante? Poderíamos dizer que o encadeamento metonímico dos significantes produz 0 encadeamento dos investimentos. $E$, se há investimento, há também afeto.

A assimilação, enquanto primeiro fato da vida psíquica, manifesta-se como repetição no sentido da reação circular, ou seja, a repetição, pelo bebê, da ação que teve êxito. Mas não podemos esquecer que todo novo esquema ou sistema de sig-

\footnotetext{
${ }^{5}$ Essa formulação é proposta por Lacan (1999), no Seminário As formações do insconsciente: "Não existe objeto a não ser metonímico, sendo o objeto do desejo o objeto do desejo do Outro, e sendo o desejo sempre um desejo de Outra coisa - muito precisamente, daquilo que falta, a, 0 objeto perdido primordialmente, na medida em que Freud mostra-o sempre por ser reencontrado." (p. 16).

6 “Le savoir est 'naturellement' investi affectivement par un suje", 1998, p. 217.
} 
nificações resulta de uma diferenciação e de uma assimilação reprodutora, general izadora e recognitiva. A assimilação reprodutora não se esgota nos esquemas sensório-motores, mas segue em outras formas de significação e re-significação, como no jogo, no fantasiar, no sonhar e nos devaneios.

Assim, do ponto de vista psicanalítico, não é possível afirmar que os alunos estejam livres para escolher o seu tema de interesse. Essa liberdade é meramente pedagógica, pois, inconscientemente, não hálivre escolha, mas sobredeterminação. Ou seja, reencontros nunca realizados, mas sempre por realizar, com novas configurações dos objetos de desejo. Objeto perdido, mas sempre por se apresentar de novo. Lacan (1966) define a repetição como a insistência de al go que nos constitui, e que, por isso, dá a impressão de sempre retornar, pois se trata da ordem si mbólica que nos sustenta e acolhe sob a forma da linguagem, e que superpõe, tanto na diacronia quanto na sincronia, a determinação do significante à do significado.

0 que se repete não é necessariamente uma situação vivida antes, pois o queé decisivo éo retorno a uma cena de desejo, isto é, uma cena vivida imaginariamente. Mas essa cena só poderá ser repetida de outra maneira, e novas maneiras de repetição ainda serão possíveis, pois o traço unário só pode ser reencontrado na sucessão de significantes, isto é, nas novas formas em que o objeto de desejo se constituirá para o sujeito a cada reencontro.

Esse processo que aconteceu com ADU, a revivescência de uma cena de desejo pela transposição na forma de uma pesquisa sobre as galáxias, lembra o processo descrito por Freud, do menino que criou um jogo de atirar e pegar de volta um objeto. Segundo a explicação freudiana, através desse jogo, o menino estava dominando uma cena que fora vivida passivamente. Esse processo implica a construção de novas significações para experiências anteriores. E éo que se observa no caso de $A D U$, que recria, sobre um plano mais abstrato, a imagem do ioiô que desejara três anos antes, conseguindo, agora, explicar o porquê do nome e das cores do ioiô.

0 retorno dos objetos perdidos (ou a reconstrução destes) em situações de aprendizagem permite, então, levantar a hipótese de que repetição inconsciente, no sentido de experiência de suspensão e superação (Aufhebung), seria constituinte do próprio processo de aprendizagem. U ma insistência repetitiva faz o sujeito reencontrar um objeto perdido, do qual restaram os significantes. Esses últimos vão dar forma aos objetos substitutos, entre eles o próprio processo de conhecimento, enquanto substituição e, ao mesmo tempo, repetição do que foi perdido. A imagem do ioiô, "um dos melhores que já vi", atualizou-se ou tornou-se pregnante pelo poder de atração do significante "galax" sobre as novas imagens ou pensamentos, "galáxia".

U ma observação de Bachelard (1884-1962), no prefácio à Psicanálisedo fogo, aplica-se de modo perfeito ao caso deADU.Trata-se da passagem em que 0 autor ana- 
lisa o que há de subjetivo no processo aparentemente objetivo de conhecimento, o que faz com que ele observe: "Basta falarmos de um objeto para nos acreditarmos objetivos. Mas, por nossa primeira escolha, o objeto nos designa mais do que o designamos" (1994, p. 1).

Na teoria do aparelho psíquico, há duas referências fundamentais para a análise desse caso. 0 conceito de rememoração (Erinnerung) como construção e o conceito de repetição (W iederholung) ou retorno de cenas infantis. 0 primeiro conceito foi apresentado por Freud na versão de 1896 da estrutura do aparelho psíquico: "O material presente em forma de traços de memória estaria sujeito, de tempos em tempos, a um rearranjo segundo novas circunstâncias - a uma retranscrição". .7 Portanto, seriam as vivências de um passado próximo que rearranjariam as vivências de um passado distante.

0 segundo conceito, o de repetição, tem sua formulação primeira na hipótese de que os traços de lembranças de cenas outrora vividas pelo sujeito repetem-se ou retornam, como foi formulado por Freud (1900a): "A cena infantil, por não conseguir uma renovação (Erneuerung), se satisfaz com o retorno (W iederkehr) como sonho". 8

Assim teríamos um núcleo formado por traços de lembrança, isto é, significantes, pronto a exercer atração sobre novas vivências. Se tomarmos a conceituação freudiana do poder de atração (Anziehehung) que exercem as representações recal cadas sobre as novas representações, pode-se formular a hipótese de que a imagem do ioiô, "um dos melhores que já vi", atualizou-se ou tornou-se pregnante pelo poder de atração do significante "galax" sobre um novo significante, "galáxia".

O conceito de repetição vincula-se ao conceito de "só-depois" ( Nachträglich), expressando a hipótese freudiana de queo acontecimento doisé que dará sentido ao acontecimento um. Esse conceito éfundamental na teoria freudiana do inconsciente. Lacan (1998a) interpretará o N achträglich (em francês, après-coup) no sentido de retroação de um significante sobre o outro. Essa interpretação está vinculada à teoria do tempo lógico, que explica como é possível que a sincronia do significante, na retroação de um tempo dois, faça existir o tempo um.

No caso galax-galáxia, uma insistência repetitiva (tempo dois) faz o sujeito reencontrar inconscientemente um objeto perdido (tempo um), do qual restaram os significantes. Esses últimos vão dar forma aos objetos substitutos, entre eles 0

\footnotetext{
${ }^{7} \mathrm{~N}$ a edição alemã de A correspondência completa de S. Freud paraW. Fliess, carta de 6 de dezembro de 1896, p. 217, está: "Von Zèt zu Zeit das vorhandenen M aterial von Erinnerungsspuren eineU mordnung nach neuen Beziehung, eine U mschrift erfährt" (MASSON, 1986).

${ }^{8}$ Freud (1972/ 1900a, p. 500) referia-se aqui ao papel desempenhado pelas lembranças infantis no processo de formação de um sonho. Na edição al emã: "Dieunbewusste Regung gleichsinnig mit einer der herrschenden Strebungen wirken kann."
} 
próprio processo de conhecimento, enquanto substituição e, ao mesmo tempo, repetição do que foi perdido.

A teorização lacaniana permite uma leitura do caso galax-galáxia como um retorno do objeto (ioiô galax) enquanto traço que se repete inconscientemente, ou melhor, tende a perdurar enquanto não for resolvido. 0 significante galax atuou na gênese do significado galáxia e, "só-depois", foi significado, isto é, quando o sujeito compreendeu que "eles botaram galax pragaláxia, porque ele éassim ó, ele é marronzinho com um monte de coisas brilhando, o marrom deveria ser o componente, e o brilhando deveria ser a estrela". A reconstrução aparece na presentificação do ioiô do passado através da expressão da frase no tempo presente: "porque ele éassim ó".

A experiência passada e a experiência presente deADU voltam-se uma sobre a outra em forma circular, já que a pesquisa sobre as galáxias que 0 jovem ADU desenvolve aos 11 anos foi condição para ele compreender o significado do ioiô galax de sua meninice. E o resto ou traço significante "galax", significante do objeto de desejo, repetiu-se até que sua insistência significante fosse re-significada.

Ora, o desejo é sempre inacabado, pois infinito einterminável. Logo, épossível seguir a interpretação do efeito Zeigarnik proposta por Lacan (1985): “ no homem, é a má forma que é prevalente. É na medida em que uma tarefa está inacabada que 0 sujeito volta a ela. É na medida em que um fracasso foi acerbo que 0 sujeito se lembra melhor dele" (p. 115).

0 efei to Zeigarnik consiste em um achado experimental de Bluma Zeigarnik. Essa pesquisadora, al una de Kurt Lewin, realizou em 1927 uma pesquisa que testou a proposição do sistema de tensão de Lewin. 0 sistema de tensão é um fator motivacional em que determinado ato ou conjunto de atos adquire uma influência diretiva sobre o comportamento até que se dissipe. Os resultados do experimento mostraram que uma tarefa não acabada deixa um estado de tensão, uma quase-necessidade. Completar a tarefa significa resolver a tensão ou descarregar a quasenecessidade. A vantagem da memória na tarefa inacabada seria devido à continuação de tensão. Lacan (1985) encontra no efeito Zeigarnik a prova da diferenciação da aprendizagem animal da aprendizagem humana. Enquanto a aprendizagem animal apresenta-se como um aperfeiçoamento organizado e finito, isto é, efeito de maturação, o efeito Zeigarnik demonstra que a aprendizagem humana acontece em função do retorno às tarefas inacabadas.

Assim, enquanto a aprendizagem animal éum desdobramento do quejá estava inscrito biologicamente, a aprendizagem humana é reconstrução a partir de restos ou traços de lembrança, isto é, do que ficou inscrito inconscientemente. E, mesmo quando os traços de lembrança são restos da sexual idade da infância, trata-se de uma inscrição psíquica e não biológica.

No caso galax-galáxia, algo se repete, e, em se repetindo, se transforma, isto é, 
o galax que, em se transformando em galáxia, foi re-significado. Essa seria a aprendizagem que se dá aos saltos, como intrusão do passado no presente. 0 inconsciente manifesta-se aqui segundo o modo da repetição de um traço que perdura. Essa repetição age até que haja a sua resolução: a resolução é a aprendizagem no sentido psicanalítico, isto é, a re-significação.

Assim, se em um primeiro momento as situações de aprendizagem chamam a nossa atenção pela presença de formações do inconsciente, como os chistes e os devaneios, em um segundo momento percebe-se que o mais significativo éo fato de que a própria forma de construir conhecimento era determinada pelas formações do inconsciente. Isto é, pela irrupção do inconscienteno discurso do falante na forma de uma enunciação que dizia respeito ao desejo inconsciente do sujeito. U m caso exemplar éo da fantasia enunciada por LU M, "eu ficaria com ciúmes se, quando eu nascesse, o meu pai viajasse para o planeta $X$, quando ele voltasse, ele estaria mais novo do que eu". N essa enunciação, aparece uma relação aparentemente indiferenciada entre os conteúdos pesqui sados e as próprias fantasias. A jovem de 11 anos de idade construiu esse enunciado a partir da informação de que há um planeta recentemente descoberto cuja distância em relação ao planetaTerra é tão grande que os passageiros de uma nave que chegasse até lá, viajando em uma velocidade próxima à da luz, e que voltasse para o planetaTerra, perceberiam a passagem do tempo de um modo diferente das pessoas que ficaram naTerra. Esse é o contexto para a hipótese que ela enunciou em seguida: se o seu pai realizasse essa viagem, o tempo que el e viveria durante o percurso não seria o mesmo tempo que ela estaria vivendo naTerra, e ela ficaria com ciúmes porque ele estaria, então, mais jovem que ela.

A jovem pesquisadora projetou-se em uma situação de relatividade do tempo. Nesse caso, o sujeito da enunciação ( sujeito do inconsciente) , que aparece na forma, "eu ficaria com ciúmes se..." , atuou, pode-se dizer, em colaboração com os processos de construção de conhecimento, pois as novas noções científicas são exploradas na forma de uma fantasia.

Segundo a psicologia genética piagetiana ( PIAGET, 1978), trata-se do emprego dos esquemas intuitivos relativos às pessoas, no caso, em relação ao pai, para a assimilação de novas noções. Do ponto de vista psicanalítico, trata-se de uma fantasia enunciada antes de voltar a sofrer um recalcamento. Esse fenômeno pode ser explicado segundo a hipótese freudiana da existência de uma relação entre os derivados do inconsciente e do pré-consciente.

U ma das formas dessa relação é a que tem origem nas moções pulsionais inconscientes que reúnem em si determinaçõesopostas, pois, segundo Freud (1915), elas pertencem, qualitativamente, ao pré-consciente, mas, de fato, ao inconsciente: de um lado, são al tamente organizadas, isentas de contradição e exploraram todas as aquisições do sistema; de outro lado, são inconscientes e incapazes de se 
tornarem conscientes. Freud identifica esse tipo de continuidade entre o inconsciente e o pré- consciente nos casos de formações de fantasias nos estádios preliminares da formação do sonho ou do sintoma, que podem se aproximar da consciência mas, assim que ultrapassam certo nível de investimento, são novamente recalcadas. Tornam-se então os resíduos altamente organizados do inconsciente que são as formações substitutivas.

Em situações favoráveis, a moção inconsciente pode agir no mesmo sentido ( gle chsinnig) que uma das tendências dominantes. 0 recalcamento nesses casosé suprimido e a atividade recalcada é admitida enquanto apoio àquela visada pelo eu.

No caso da fantasia de LUM, as duas formas de relação ocorreram. Por um lado, um desejo inconsciente aparece de forma altamente organizada, confundindo-se com um pensamento pré-consciente, pois, além da forma optativa caraterística dos devaneios, há aqui uma relação condicional entre as duas orações que enunciam a fantasia: "eu ficaria com ciúmes se... o meu pai viajasse". E, por outro lado, há uma cooperação entre as formações pré-conscientes e inconscientes, pois a fantasia atua no mesmo sentido que as novas noções científicas que estão sendo elaboradas pela jovem pesquisadora. Isto é, na medida em que o desejo inconsciente fornece elementos para a construção de uma noção, ao mesmo tempo em que a nova noção de relatividade do tempo e de velocidade da luz permite que esse desejo seja pronunciado e, portanto, elaborado ou resolvido.

0 caso deADU mostra uma situação em que aparece uma circulação dos derivados inconscientes ao pré-consciente, mas também uma circulação ou trânsito do pré-consciente ao inconsciente. Primeiramente, um desejo inconscientizado de obter um brinquedo atua, inconscientemente, na escolha de um determinado tema de investigação. Mas somente devido ao trabalho de pesquisa (processo de aprendizagem), isto é, graças às formações pré-conscientes, queo sujeito tem acesso a essa lembrança que ficara inconscientizada. 0 menino que nunca realizara o desejo de obter o ioiô galax escolheu como tema de pesquisa estudar as galáxias. E, nessa pesquisa sobre as galáxias, restos de lembranças de infância foram transformados, isto é, foram substituídos e simbolizados na operação inconsciente de reescritura dessas lembranças.

Para Piaget, operar é transformar; para Freud e Lacan, em uma formação do inconsciente, há uma reescritura, transposição ou reordenamento de moções pulsionais e de traços de lembrança. Assim, o conceito de sujeito do conhecimento pode ser submetido a duas interpretações. U ma primeira leitura mostra que pensamos a partir de uma estrutura epistêmica da qual nada sabemos, isto é, o sujeito epistêmico. U ma segunda leitura, na qual se incluem os achados da teoria psicanalítica, mostra que, se agimos como sujeitos do conhecimento, o fazemos sempre a partir do que foi vivido singularmente, mesmo que essa vivência tenha sido inconscientizada. 
Segundo a concepção piagetiana, a inteligência organiza o mundo organizando-se a si mesma ( PIAGET, 1970). Podemos aplicar essa idéia para imaginar uma auto-referencialidade da qual não podemos nunca nos subtrair, sob risco de desaparecermos enquanto sujeitos.

Esse estudo mostra duas dimensões do sujeito da aprendizagem: por um lado, o sujeito dividido, sujeito das formações do inconsciente, por outro lado, o sujeito dos processos cognitivos. Este sujeito interage com o ambiente, enquanto que aquel e transforma ou metaboliza através de formações do inconsciente quaisquer conteúdos, processos cognitivos ou recursos tecnológicos. No sujeito dos processos cognitivos, a aprendizagem é um processo de construção. No sujeito do inconsciente, a aprendizagem é um processo de transformação por resolução ou dissolução de antigas formações em novas formações do inconsciente.

Recebido em 10/ 10/ 2001. Aprovado em 5/ 2/ 2002.

\section{BIBLIOGRAFIA}

BACHELARD, G. (1949/ 1994) A psicanálise do fogo. São Paulo: Martins Fontes.

CAON, J. L. ( 1998) "Da existência analfabética à existência alfabetizada”, Revista do Geempa, 6, outubro, p. 37-52.

CIFALI, M. (1998) Le lien éducatif: contre jour psychanalytique, Paris, PUF.

FREUD, S. (1972) Studienausgabe, Frankfurt a Main, Fischer.

(1987a) GesammelteW erke. Frankfurt a Main, Fischer.

(1987b) Edição standard brasileira das obras psicológicas completas de

Sigmund Freud (VIII), 2. ed., tradução e revisão dirigidas por Jayme Salomão, Rio de Janeiro, Imago.

(1900) "A interpretação dos sonhos", v. V.

(1905) "Os chistes e sua relação com o inconsciente", v. VIII.

(1908a) "Sobre as teorias sexuais das crianças", v. IX.

(1908b[1907]) "Escritores criativos e devaneios", v. IX.

(1915) "O inconsciente", v. XIV.

(1925) "A negativa", v. XIX.

LACAN, J. (1966) Écrits, Paris, Éditions du Seuil.

(1978/ 1985) 0 Seminário, livro 2: 0 eu na teoria de Freud e na técnica

da psicanálise, Rio de Janeiro, Jorge Zahar.

(1998) Escritos, Rio de Janeiro, Jorge Zahar.

(1999) O Seminário, livro 5, As formações do insconsciente, Rio de

Janeiro, Jorge Zahar.

MASSON, J. M. (1986) A correspondência completa de S. Freud paraW. Fliess,1887-

1904, Rio de Janeiro, Imago.

MILLOT, C. (1979/ 1987). Freud antipedagogo, Rio de Janeiro, Jorge Zahar. 
PAPERT, S. (1985). Logo: computadores e educação, São Paulo, Brasiliense. . e TURKLE, S. (1990) "Epistemological pluralism: styles and voices within the computer culture" . E \& L, M emo n. 3. (Disponível na Internet via WWW. URL: http: / / www.media.mit.edu/ groups/ el).

PIAGET, J. (1937/ 1970) La construcción de lo real en el niño, 3. ed., Buenos Aires, Editorial Proteo.

(1945/ 1978) A formação do símbolo na criança. Tradução de Álvaro Cabral e C. Oiticica, Rio de Janeiro, Guanabara Koogan.

(1977/ 1995) Abstração reflexionante. Tradução Fernando Becker e Petronilha B. Gonçalves da Silva, Porto Alegre, Artes Médicas.

. \& GARCIA, R. (1987) Vers une logique des significations, Genebra, Murionde.

SAGAN, C. (1997) Contato, São Paulo, Companhia das Letras.

\author{
Marta D'Agord \\ Rua Riveira, 600 \\ 90670-160 Porto Alegre RS \\ mdagord@terra.com.br
}

